\title{
Elimination of trans-fatty acids in the Eastern Mediterranean Region ${ }^{1}$
}

Citation: Elimination of trans fatty acids in the Eastern Mediterranean Region. East Mediterr Health J. 2021;27(6):639-640. https://doi. org/10.26719/2021.27.6.639

Copyright (C) World Health Organization (WHO) 2021. Open Access. Some rights reserved. This work is available under the CC BY-NC-SA 3.0 IGO license (https://creativecommons.org/licenses/by-nc-sa/3.o/igo).

\section{Introduction}

Noncommunicable diseases (NCDs) are the leading causes of mortality globally, responsible for almost $68 \%$ of deaths in the WHO Eastern Mediterranean Region, while unhealthy diet is a major contributing factor (1). Countries are therefore working towards reducing diet-related NCD risk factors, including the consumption of trans-fatty acids (TFA). The Eastern Mediterranean Region has one of the highest levels of TFA in its food supply (2).

Replacing industrially produced TFA (iTFA) with healthier fats/oils is feasible and cost-effective, and elimination of iTFA by 2023 is a global and regional priority for WHO (2). In May 2018, WHO launched the REPLACE action package to eliminate iTFA from the global food supply (3). As part of providing technical support and regulatory capacity-building to the countries of the Eastern Mediterranean Region, a virtual training workshop was held in the WHO Regional Office for the Eastern Mediterranean, Cairo, Egypt, 10-11 August 2020 (4). The workshop aimed to provide countries with technical guidance from WHO and 'Resolve to Save Lives' [an initiative of the global public health organization Vital Strategies (5)]. Specifically, the workshop aimed at:

- identifying progress, enablers and barriers to eliminating TFA in EMR countries;

- building capacity and relationships with partners working on TFA regulations in the Region;

- facilitating cross-regional learning among nutrition focal points, experts and stakeholders; and

- identifying specific support needs and creating follow-up plans to provide technical support.

\section{Summary of discussions}

Global progress over the past 12 months was outlined, including best practice TFA policies coming into effect in two countries (Lithuania and Saudi Arabia) and being passed in two others (Brazil and Turkey). In addition, draft policies that meet the best practice criteria have been proposed and notified in India and Nigeria. In total, 14 coun- tries had best practice TFA policies being implemented in 2020, and 40 countries had measures that would come into effect by 2022. Most countries do not, therefore, have policies in place yet and most policy action to date has been in higher-income countries in the WHO Americas and European regions. Consequently, there is still a long way to go to achieve global elimination by 2023 .

Several enablers or solutions for accelerating progress were identified. Policy preparation could be facilitated by compiling evidence, publishing technical reports, mapping existing legislations, building on existing national nutrition policies/strategies, calculating costs/ benefits of alternative policies, and establishing or strengthening multisectoral coordination mechanisms. During the policy development phase, progress can be accelerated by having strong regulatory bodies, writing comprehensive, legally sound and enforceable rules, and building political support. Policy implementation could be facilitated by educating stakeholders and providing guidance on compliance and enforcement of the rules. Finally, monitoring can be strengthened by including monitoring and evaluation mechanisms within regulatory measures and strengthening laboratory capacities.

\section{Recommendations}

\section{To WHO}

- compiling evidence and publishing technical reports;

- mapping existing laws/legislations and building on existing national nutrition policies/strategies;

- calculating costs/benefits of alternative policies; and

- establishing a multisectoral technical committee and building on existing coordination mechanisms.

\section{To Member States}

- having strong regulatory bodies;

- writing comprehensive, legally sound and enforceable rules; and

- building political support (e.g. support of parliamentarians, other ministers beyond health). 


\section{References}

1. World Health Organization. Noncommunicable diseases country profiles 2018. Geneva: World Health Organization; 2018 (https://www.who.int/nmh/publications/ncd-profiles-2018/en/).

2. World Health Organization Regional Office for the Eastern Mediterranean (WHO/EMRO). Strategy on nutrition for the Eastern Mediterranean Region 2020-2030. Cairo: WHO/EMRO; 2019 (https://apps.who.int/iris/handle/10665/330059).

3. World Health Organization. REPLACE: An action package to eliminate industrially produced trans-fat from the global food supply. Geneva: World Health Organization; 2019 (https://www.who.int/teams/nutrition-food-safety/replace-trans-fat).

4. World Health Organization Regional Office for the Eastern Mediterranean (WHO/EMRO). Elimination of trans fatty acids in the Eastern Mediterranean Region, Cairo, Egypt 10-12 August 2020. Cairo: WHO/EMRO; 2020 (https://applications.emro.who.int/ docs/WHOEMNUT287E-eng.pdf?ua=1).

5. Vital Strategies. Resolve to save lives. New York: Vital Strategies; 2020 (https://resolvetosavelives.org/). 